\title{
Olhar, tecnologia e arte
}

Milton Sogabe é docente da Universidade Anhembi Morumbi (2017-atual), graduado em artes plásticas pela FAAP-SP, mestrado e doutorado em Comunicação e Semiótica pela PUC-SP, pós-doutorado pela Universidade de Aveiro. Bolsista PQ desde 2008. Pesquisa e produz obras na confluência entre arte, ciência e tecnologia desde os anos 80 .

<miltonsogabe@gmail.com>

ORCID: 0000-0003-1286-9013
Resumo $\mathrm{O}$ ser humano passa por um processo de ciborguização, que foi intensificado com a tecnologia digital. Várias partes do corpo têm possibilidades de serem substituídas por órgãos artificiais que se aproximam cada vez mais dos originais. Ao mesmo tempo, esses conhecimentos vão ampliando as extensões tecnológicas do nosso corpo, tornando os androides cada vez mais próximos ao humano.

Nesse contexto, a visão como um dos principais sistemas sensoriais para a nossa sobrevivência no ambiente, vem ganhando potencial para ser alterada com aparatos tecnológicos, possibilitando deficientes visuais a terem parte da visualidade recuperada, e ampliando o potencial visual, num futuro próximo. $\mathrm{O}$ universo do olhar humano é apresentado aqui, no diálogo entre arte, ciência e tecnologia.

Palavras chave Ciborgue, Visão artificial, Corpo pós-biológico, Dispositivos visuais, Arte-tecnologia.

\section{Eye, technology and art}

Abstract The human being goes through the cyborgization process, that has been intensified with digital technology. Several parts of the body are likely to be replaced by artificial organs that are getting closer and closer to the original ones. At the same time, this knowledge is expanding the technological extensions of our body, making androids closer to human.

In this context, vision as one of the main sensory systems for our survival in the environment, has been gaining potential to be changed with technological apparatuses, enabling visually impaired to have part of their visuality recovered, and expanding visual potential in the near future. The universe of the human eye is presente here, in the dialogue between art, science and technology.

Keywords Cyborg, Artificial Vison, Post biological body, Visual devices, Art-technology. 


\section{Introdução}

Pós-humano, corpo pós-biológico, homo sapiens 2.0 são alguns dos termos com os quais convivemos cada vez mais. Embora pareçam temas de ficção científica, são fatos que já estão acontecendo hoje. Já estamos habituamos a ter de confirmarmos na Internet que "não somos robôs", para termos acesso a algumas informações. A robô Sofia ganhou cidadania árabe, e o documento de identidade de Neil Harbisson o reconhece como sendo um ciborgue. Esse contexto todo acontece devido a dois fatores na relação corpo/tecnologia, por um lado nosso corpo adquiriu uma grande capacidade se transformar com o desenvolvimento científico e tecnológico, através de cirurgias e implantes, e por outro, ampliamos cada vez mais o potencial do sistema de extensões tecnológicas de nosso corpo, do muscular ao mental. Ciborgue e androide se aproximam cada vez mais.

No século XXI, os graus de mutação do nosso corpo são muitos, que vão desde as cirurgias, até os implantes tecnológicos e a engenharia genética. $\mathrm{O}$ desenvolvimento sobre o conhecimento do corpo encontra um similar, na produção das suas extensões artificiais, que alimentam o mundo das máquinas e do ciborgue. Teorias como a da singularidade tecnológica, onde o desenvolvimento tecnológico aponta para o superamento do humano pelas máquinas, nos levará a imortalidade, segundo Kurztweil, através da fusão homem-máquina e silício-carbono. (KURZTWEIL, 2005)

Desde a antiguidade o ser humano resolve seus problemas físicos através de próteses, cirurgias e invenções científicas e tecnológicas, como os remédios e os dispositivos, denominados hoje de tecnologia assistiva. O desenvolvimento das diversas áreas do conhecimento, contribuem para que o ser humano tenha uma vida melhor sobre esse aspecto físico. Essa capacidade de interferência no corpo humano, ultrapassa as características mecânicas e atinge um alto grau através da manipulação genética, transformando o homo sapiens em homo deus (HARARI, 2016).

Neste artigo delimitamos essa discussão no campo visual, e mais especificamente no olho. Embora pareça muito reduzido, vemos que os fatos constituem um fractal, onde a estrutura da discussão do campo maior, do corpo como um todo, se reflete nesta pequena parte, na discussão sobre o olho.

O olho ou globo ocular humano faz parte do sistema visual humano que é binocular, e é sensível a uma faixa do espectro eletromagnético, denominado de luz visível. O sistema visual é constituído por diversas partes que desenvolvem atividades ópticas, químicas, elétricas e neuronais, participando da construção da imagem em nossa mente.

Quando vemos a fotografia de uma imagem projetada na nossa retina, isso pode nos confundir, achando que temos uma imagem formada lá, mas no caso, essa imagem é construída pela câmera fotográfica e o aparato que permite essa câmera visualizar e captar esse fenômeno na nossa retina. 0 que temos de fato na retina é uma projeção luminosa, ou seja, um estímulo lu- 
minoso, que não representa uma imagem na nossa mente, pois ainda precisa se transformar em estímulo elétrico, percorrer o nervo óptico até chegar ao cérebro, onde acontece a construção da imagem e o armazenamento.

Como parte do corpo humano, o olho é um produto biológico-cultural, que vem passando também por interferências externas como o uso de dispositivos ópticos, cirurgias e implantes.

Paralelamente, presenciamos todo esse conhecimento sendo utilizado para o desenvolvimento de um sistema visual artificial, que é utilizado nas máquinas, seja desde um simples dispositivo óptico até sistemas visuais inteligentes mais complexos na robótica.

Organizamos neste artigo, a discussão sobre a relação olho/tecnologia, através de três situações. 1- Dispositivos ópticos, externos ao nosso corpo, que auxiliam e ampliam nossa visão. 2- Implantes ópticos, que acontecem de forma invasiva no nosso corpo, buscando restaurar a visão. 3- Visualidade nas máquinas, são dispositivos semelhantes ao nosso sistema visual, que são produzidos para utilização nas máquinas.

\section{Dispositivos Ópticos}

A formação da imagem na nossa mente tem como primeira etapa um fenômeno óptico, que está regido pelas leis da natureza. O ser humano só percebe uma faixa do espectro eletromagnético, denominada de luz visível que é emitida ou refletida pelo mundo físico ao nosso redor. Ela penetra no nosso olho, passando por um sistema complexo de elementos e é projetada na superfície da retina. Depois o sistema visual dá sequência a outros tipos de atividades, que já não são somente ópticos, mas químicos e elétricos até chegarem no córtex visual, onde se forma a imagem.

O fenômeno óptico está presente na natureza em alguns objetos e situações, como as lentes e a câmera escura. 0 cristalino que faz parte do olho é como uma lente biconvexa e transparente. A câmera escura é um aparato semelhante ao nosso olho, pois a luz que entra pela abertura de um dos lados da câmera, projeta uma imagem luminosa invertida na parede oposta. Porém, a semelhança fica por aí, pois nosso olho é mais complexo, e está conectado a nossa mente que o controla, além de termos uma visão binocular. A partir desses dois elementos surgiram vários outros dispositivos visuais, que ampliaram a capacidade da visão humana, tanto para visualizar o minúsculo como o longínquo, além de outras faixas do espectro eletromagnético não acessíveis aos nossos olhos.

Lentes

As lentes estão na natureza, na Caverna de Zeus, em Creta, foram encontradas lentes de rocha de cristal (quartzo) com boa qualidade óptica. (SINES, 1987, 193) 
Essas lentes descobertas há 3.500 anos atrás, evoluíram através do controle da tecnologia do vidro. No antigo Egito os artesãos de vidros já tinham muito conhecimento, utilizavam a técnica do vidro soprado para moldar formas ocas de vidro e produziam também lentes. Porém as primeiras lentes surgiram há pelo menos 3.500 anos em Creta. A utilização delas era variada, entre joalheria, decoração, para acender fogo e como forma de ampliação visual. (ENOCH, 274)

$\mathrm{Na}$ China antiga as lentes já existiam e eram mais usadas para acender fogo, além de relatos sobre o uso de volumes esféricos de vidro com água dentro, para cauterizar aberturas na pele, através da concentração de calor que provocavam. (LAUFFER, 1915, 174)

As lentes começaram a ser utilizadas na qualidade da visualização da imagem, através da construção das lentes monoculares, e nos binóculos somente no final dos anos 1.300, na Itália, Alemanha e Austria. (ENOCH, 274)

Nesse contexto descobriram que as lentes poderiam servir para o tratamento da presbiopia, mais conhecida como vista cansada. A partir dessas lentes esféricas desenvolveram lentes para o astigmatismo. (SCHOR, 2003,11) Leonardo da Vinci desenvolveu vários estudos de óptica e desenhou

Fig 1. Projeto de Leonardo da Vinci para lentes de contato.

Fonte: (ENLIGHTENMENT MATTERS, 2006) https://enlightenmentmatters. files.wordpress.com/2016/04/leonardodavincicontactlenses.jpg esboços (Figura 1) do que se assemelham às lentes de contato em 1508 e
René Descartes também apresentou projeto de lentes de contato em 1637. (HOFSTETTER, GRAHAM, 1953, 41)

Através das lentes foram construídos vários aparatos de visualização, para aumentar nossa capacidade para ver o distante e o minúsculo, como telescópio e o microscópio.

\section{Telescópio}

No final do século XVI, com o aprimoramento das lentes, encontramos aparatos que se assemelham com os telescópios. Porém, sobre a autoria de sua invenção existe uma polêmica, em torno de vários nomes como, Leonard Digges que menciona um sistema de lentes côncavas e convexas armadas sobre uma estrutura, mas sem o tubo, além de Giovanni Battista della Porta e outros. A primeira patente de um telescópio foi requerida em 1608, por Hans Lippershey, mas outros relatam ter criado o telescópio, como Zacharias Jansen e Adrien Metius. Galileu também declara ter recebido notícias dessa invenção e a partir das informações aprimorou o aparato, para suas observações. (ÉVORA, 1989)

De entretenimento a instrumento científico, o telescópio ampliou a visão humana para uma escala do muito distante, permitindo descobertas revolucionárias.

Com o desenvolvimento tecnológico os telescópios foram ampliando nossa capacidade de visualizar além do espectro de luz visível, para a amplitude dos infravermelhos, raios X, micro-ondas e radiofrequência nos finais do século XX, traduzindo para nosso olhar, imagens com aspectos nunca antes vistos a olho nu. 
Experiencias com envio de câmeras em misseis e espaçonaves, para vermos mais longe marcam nossa história.

O telescópio espacial Hubble, lançado ao espaço em 1990, representa nossa capacidade ampliada de ver o longínquo, observando também o infravermelho e o ultravioleta. Ele já enviou centenas de milhares de imagens do universo, ampliando nosso conhecimento, e novos instrumentos são acoplados, para atividades específicas. "O conjunto atual de instrumentos do Hubble inclui a Wide Field Camera 3 (WFC3), o Cosmic Origins Spectrograph (COS), a Advanced Camera for Surveys (ACS), o Space Telescope Imaging Spectrograph (STIS) e os sensores de orientação fina (FGS)." (HUBBLE, 2019)

A Voyager é outro projeto que, em 1977, enviou nosso olhar para viajar pelo espaço interestelar tendo passado por Júpiter, Saturno, Urano e Netuno. São duas sondas lançadas com 15 dias de diferença, cada qual com uma missão. As sondas enviam informações através de ondas de rádio que são captadas por potentes radiotelescópios situados na Terra. (VOYAGER, 2019)

\section{Microscópio}

O microscópio também é mais um invento da época do Renascimento, quando os aparatos técnicos transformavam os pensamentos humanos, no mesmo nível das teorias filosóficas nos livros. Com esses aparatos técnicos a ciência ganha um grande impulso, na observação da natureza. (ROSSI, 1989)

A autoria do microscópio também é polêmica, porém há registros de que tenha sido inventado na Holanda, por Zacharias Jansens, antes de 1590. Outros aprimoraram a descoberta e realizaram observações de microorganismos, como Antony van Leeuwenhoek, comerciante e cientista e Johann Nathanael Lieberkühn, um cientista. (HOGG, 1854)

Os microscópicos ópticos, constituídos por um conjunto de lentes para observar algum material iluminado por fonte de luz visível, podem ampliar até 2 mil vezes, mas com a construção de microscópios eletrônicos, que usam fonte de feixe de elétrons, ampliamos nossa capacidade de visualização, por meio de feixe de elétrons, para milhares de vezes. 0 conceito e construção dos microscópios eletrônicos de varredura datam dos anos 30. (DEDAVID, 2007)

Fig 2. Resolução. Esquema de Sebastião G. dos Santos Filho (LSI/PSI/EPUSP) Fonte: (SANTOS FILHO, 2019) http:// www.lsi.usp.br/ acseabra/pos/5749_ files/AFM_STM.pdf

\begin{tabular}{|l|c|l|}
\hline \multicolumn{1}{|c|}{ O que a vista alcança } \\
\hline Equipamento & $\begin{array}{c}\text { Aumento de } \\
\text { imagens }\end{array}$ & \multicolumn{1}{c|}{ Amostras } \\
\hline Olho humano & $\mathbf{1 v e z}$ & Cristais de neve \\
\hline $\begin{array}{l}\text { Microscopio } \\
\text { estereoscópico }\end{array}$ & $\mathbf{7 0} 150$ vezes 120 vezes & $\begin{array}{l}\text { Insetos muito pequenos, peças de } \\
\text { relojoaria, algas }\end{array}$ \\
\hline Microscópio ótico & $\begin{array}{l}\text { Glóbulos vermelhos do sangue, } \\
\text { bactérias, células animais e vegetais }\end{array}$ \\
\hline $\begin{array}{l}\text { Microscópio eletrônico de } \\
\text { varredura }\end{array}$ & 20 a 100000 vezes & $\begin{array}{l}\text { Superfície de órgãos animais e } \\
\text { vegetais, circuitos impressos, } \\
\text { componentes da superfície de metais }\end{array}$ \\
\hline $\begin{array}{l}\text { Microscópio eletrônico de } \\
\text { transmissão }\end{array}$ & 1000 a 500000 vezes & $\begin{array}{l}\text { Vírus, moléculas orgânicas grandes, } \\
\text { estruturas de células }\end{array}$ \\
\hline $\begin{array}{l}\text { Microscópio de } \\
\text { tunelamento }\end{array}$ & 100 milhões de vezes & $\begin{array}{l}\text { Moléculas, átomos de superficie de } \\
\text { metais. }\end{array}$ \\
\hline
\end{tabular}


Com o avanço da mecânica quântica foi possível a construção do microscópio de tunelamento, criado em 1981, pelos cientistas Gerd Binning e Heinrich Roher, da IBM de Zurich, aumentando para 100 milhões de vezes a observação.

\section{Câmera Fotográfica}

O fenômeno da câmera escura já é conhecida há muito tempo. É o mesmo fenômeno que acontece no nosso olho quando olhamos para algo. $\mathrm{O}$ que muda com o avanço tecnológico e científico é principalmente a forma de registro da imagem, que no seu início é baseada em processos fotoquímicos, depois magnéticos e atualmente digital. No contexto digital ganha muitos outros aspectos que vão além da simples captação de imagem, adquirindo capacidades que vão do armazenamento até a transmissão sem fio, para outros dispositivos.

A câmera fotográfica é um corpo técnico que está conectada quase sempre ao corpo humano formando um híbrido que afeta a imagem registrada no tempo e no espaço, de acordo com suas características técnicas específicas, para cada ambiente, que envolve as condições físicas e sociais (PERES, 2018). Mencionamos quase sempre, pois com as câmeras de vigilância, elas se dissociaram do nosso corpo, funcionando isoladamente. Começamos dentro das primeiras câmeras escuras, e estas diminuíram tanto de tamanho no seu percurso que acabaram dentro do nosso próprio no nosso olho, como veremos mais adiante.

Atualmente as câmeras passam por uma transformação paradigmática, ao prescindirem das lentes. Já tinham diminuído a dimensão do corpo da câmera escura, quase eliminando-a ou transformando-a em uma superfície, diminuíram de tamanho até se tornarem microcâmeras, e agora com a tecnologia denominada Optical Phased Array (OPA), desenvolvida pela Caltech, Instituto de Ciência e Engenharia, na California, as câmeras, se é que ainda possamos denomina-las assim, já não necessitam de lentes, o que deve afetar áreas como a astronomia, além do mundo dos celulares. (PERKINS, 2017)

\section{Imagens microscópicas e arte}

A nanotecnologia nos permitiu enxergar um universo tão pequeno quanto o átomo, através de microscópio eletrônicos. A arte não poderia deixar de explorar esse universo, levando artistas em parceria com engenheiros e cientistas a produzirem imagens nessa escala.

Vik Muniz, um fotógrafo e pesquisador da imagem, brasileiro, em parceria com o Laboratório de Mídia do MIT (Massachusetts Institute of Technology), produziram imagens vistas apenas através de microscópios. 
Em parceria com o designer Marcelo Coelho, e o cientista Rehmi Post, produziram imagens em grãos de areia, com um milímetro de largura. "Sand Castels" (Figura 3) é uma série de imagens de castelos. Uma linha pode medir entre 0,4 a 1,0 micrômetro, que é equivalente a milionésima parte do milímetro. (SOKOL, 2014)

Fig 3. Imagem da série Sand Castles. Imagem em grão de areia. Vik Muniz, Marcelo Coelho e Rehmi Post. Fonte: (CREATORS, 2014) https://www. vice.com/en_us/article/xy4zj3/creatingsand-castles-with-a-single-grain-of-sand

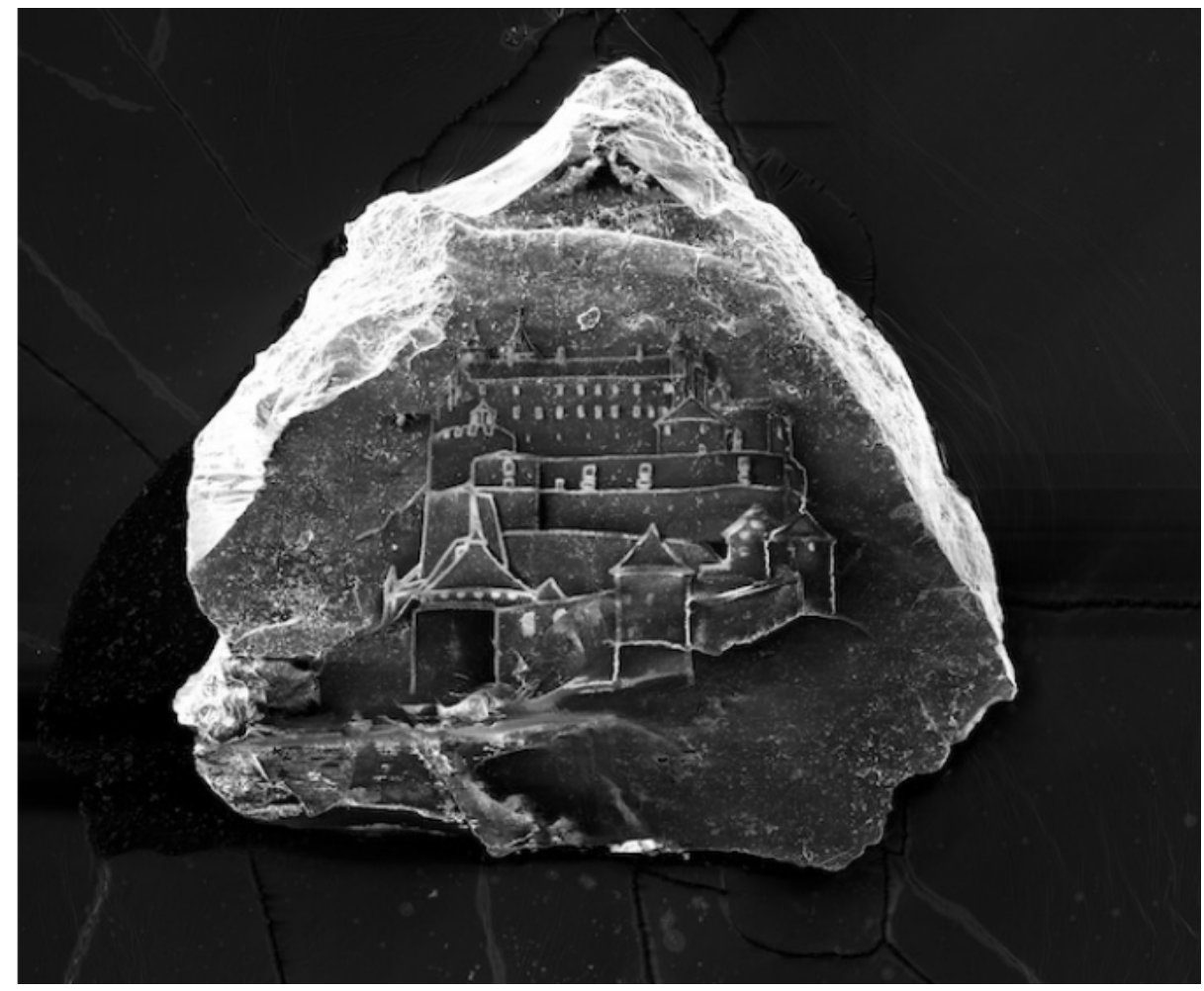

Outra série de imagens, "Colônias", foi produzida em parceria com Tal Danino, no laboratório do Dr. Sangeeta Bhatia no Instituto Koch para Pesquisa Integrada do Câncer. Foram utilizadas bactérias de câncer para formarem retratos (Figura 4) e padrões visuais.

O processo de criação dessas imagens tem três etapas. A primeira etapa consiste em criar uma imagem-base usando técnicas de fotolitografia. Depois disso, moldamos uma espécie de carimbo de borracha a partir dessa primeira imagem, e carimbamos essa figura usando uma substância grudenta; é nessa substância que as células cancerosas ou as bactérias irão grudar. 0 último passo é inserir as células cancerosas ou bactérias à superfície marcada, esperar até que elas grudem na substância pegajosa e observar o resultado por um microscópio. Com ele, podemos observar as células e bactérias individualmente. Quando olhamos mais de longe, podemos ver a gravura final. (DANINO, apud CREATORS, 2014) 


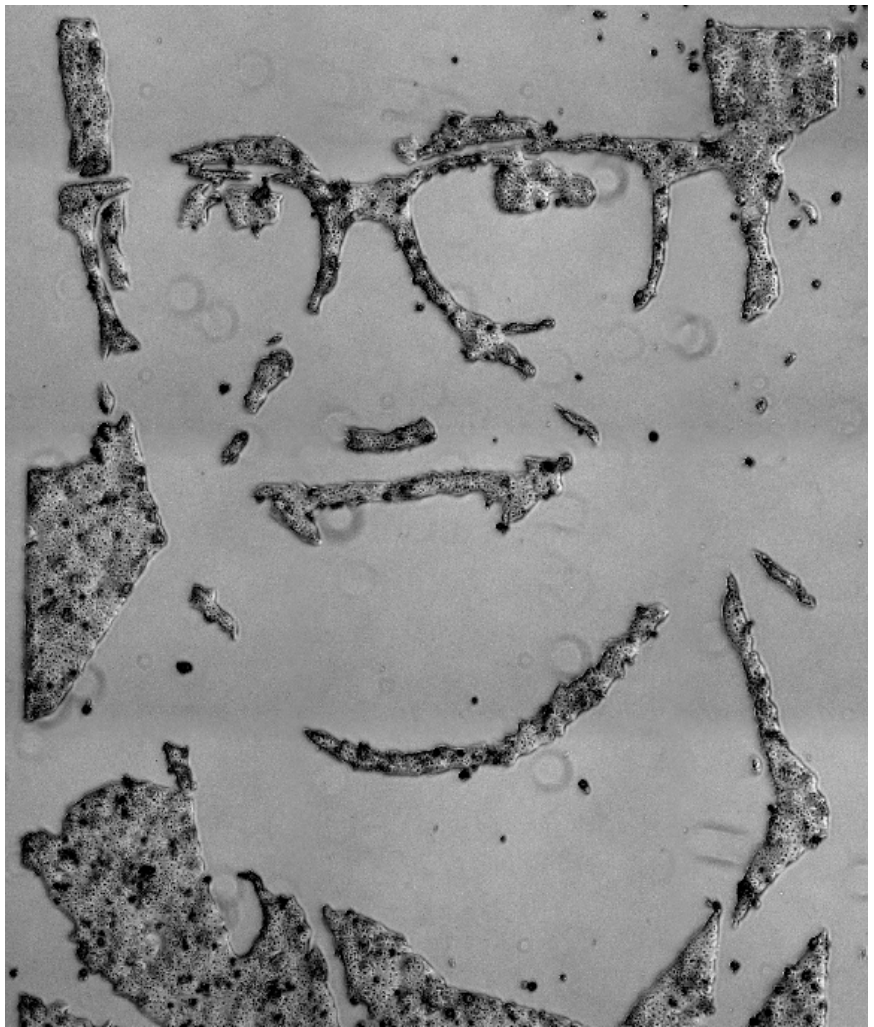

Fig 4. Autorretrato de Tal Danino feito de células do fígado. "Série Colônias". Gravura de Células do Fígado. Cortesia de Vik Muniz e Tal Danino Fonte: (CREATORS, 2014) https://www. vice.com/pt_br/article/8qdy4x/colonias-vik-muniz-e-tal-danino-transformam-celulas-vivas-em-arte
Arte, ciência e tecnologia ajudam a explorar nosso mundo em uma escala atômica, permitindo visualizar esse universo e construindo imagens visíveis apenas através dos microscópios.

\section{Implantes Ópticos}

As interferências para correção da nossa visão ultrapassam o uso de dispositivos como os óculos ou lentes de contato, tendo a possibilidade de passarmos por cirurgia também.

Schor declara que a correção de miopia, hipermetropia, astigmatismo e presbiopia, através de cirurgia é simples, porém:

\begin{abstract}
A introdução das lentes de contato rígidas, depois gelatinosas e das cirurgias refrativas corneanas e intra-oculares, se deu basicamente guiada por mudanças comportamentais na sociedade, como padrões estéticos e não pela ineficiência dos óculos. Até hoje quando orientamos pacientes pré-cirúrgicos, enfatizamos que a cirurgia refrativa deve ter como objetivo a diminuição da dependência aos óculos ou lentes de contato, e que provavelmente a visão do paciente deverá ser ligeiramente inferior à conseguida com a correção anterior. (SCHOR, 2003, 36)
\end{abstract}

Embora os óculos resolvam a maior parte dos problemas, a justificativa das cirurgias passa mais por questões de comodidade na prática de esportes, inadaptação às lentes de contato, e outros aspectos estéticos.

Com o surgimento da tecnologia digital, pesquisas para a criação de um olho artificial, que possa ser implantado no lugar do olho natural, desenvolve-se em diversas direções.

Encontramos diversos tipos de dispositivos ópticos conectados ao corpo, com graus de invasão diferenciados, indo desde dispositivos externos até os conectados diretamente ao cérebro.

Apresentamos 3 tipos de sistemas tecnológicos conectados ao sistema humano: sistemas externos, sistemas semi-invasivos, sistemas invasivos. Por último, trazemos um tipo de modificação que não é através de um implante, mas através do tratamento com manipulação genética. 


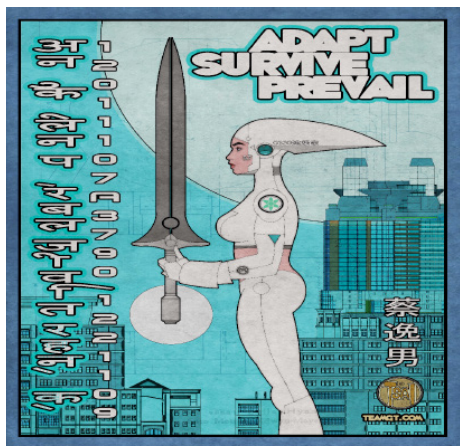

Fig 7. Obra de Tsai. “Adapt :: Survive :: Prevail - Linda" February 16th, 2013 Fonte: (TSAI, 2019) http://teamgt.com/ page/2/1d9cfe58894
A produção de Tsai durante esse período teve como lema de suas obras "Adaptar, sobreviver, prevalecer" (Figura 7), refletindo sua vida e de sua esposa, a quem dedicou a ilustração ao lado.

\section{Sistemas semi-invasivos}

Denominamos aqui de sistemas semi-invasivos aqueles que apenas substituem o olho, mas sem conectarem-se ao restante do sistema visual. Tal como o olho de vidro, que tem uma função mais estética, pois não afeta o sistema visual. Ele apenas cobre um olho danificado, como uma capa, ou substitui-o totalmente, podendo ser produzido semelhante ao outro olho normal chamando menos atenção.

Nesse sentido, o olho de vidro é apenas um objeto inserido no corpo, sem nenhuma conexão que influencie o sistema visual, corrigindo algum problema.

\section{- Rob Spence}

Assim é o caso de Rob Spence, que implantou um olho artificial, porém com uma diferença, pois o olho possui uma microcâmera (Figura 8), tornando-o um "eyeborg", um ciborgue visual. Spencer perdeu a vista direita num acidente com arma quando era criança, e para adaptar sua visão, em 2008, implantou uma câmera adaptada no lugar de seu olho direito, conectada via wifi a um sistema externo que permite a visualização (Figura 9). Esta câmera consegue gravar até 3 minutos, devido a um problema de aquecimento do equipamento. Quando em funcionamento, um led vermelho se acende, revelando que está gravando com seu olhar.

Spence é cineasta e realizou um documentário intitulado "Deus Ex: The Eyeborg Documentary", a pedido da empresa Square Enix, que publicou o jogo "Deus Ex: Revolution Human". Adam Jensem é o personagem do jogo, que tem aprimoramentos através de órgãos tecnológicos, que ampliam a capacidade de seu corpo. Nesse sentido o documentário de Spence é pesquisar e apresentar pessoas que possuem vários tipos de próteses. (SPENCE, 2011)

Rob Spence é um cineasta canadense, que tem um implante de câmera no lugar do olho direito que perdeu aos 9 anos de idade. 0 olho-câmera wireless não está conectado a sua mente, mas sim a um dispositivo externo, que permite visualizar e gravar o que vê.

Spence declara que o comportamento das pessoas em frente a uma Fig 9. Dispositivo que permite ver imagem captada.

Fonte: (SPENCE, 2011) https://eyeborgproject.tv/ted-talks/ câmera se modifica, assim gravando só com o olhar, a situação pode ficar mais natural. Ele grava e depois informa como gravou e solicita uma assinatura para autorização do material. 
A maioria das pessoas faz relação direta com o episódio "The Entire History of You", do seriado Black Mirror, onde as pessoas têm um implante que permite gravar tudo que veem e que podem ser reproduzidos, como suas lembranças, ou requeridas por outras pessoas. Nesse sentido, a ficção começa a se tornar realidade.

\section{Sistemas invasivos}

Este tipo de sistema é implantado no nosso corpo afetando o sistema visual e a construção de imagem no cérebro.

O sistema visual artificial que o Dr. Wiliam Dobelle começou a desenvolver em 1968, envolve uma invasão corporal, com o implante de uma matriz de eletrodos no córtex visual, que é conectado a um sistema externo através de um plug na caixa craniana. Esse sistema é composto por óculos, que possui uma câmera no lado direito e um sensor de distância no lado esquerdo. $O$ sistema permite apenas que o deficiente visual consiga se movimentar no espaço recebendo pontos de luz dos objetos, num campo de $5 \mathrm{~cm} \times 20 \mathrm{~cm}$, onde percebe pontos de luz. Nessa experimentação, o objetivo é ampliar a quantidade de eletrodos para conseguir melhor definição da imagem produzida. (DOBELLE, 2000)

Na Universidade de Tübingen, na Alemanha outra experimentação foi realizada com a implantação de um chip, de 3x3mm, na retina de uma paciente cega, Miika Terho. (Figura 10). O chip ficava conectado a uma bateria que era usada como um colar pelo paciente. Quando o chip recebia um estímulo luminoso, ele estimulava as células saudáveis da retina, enviando os sinais para o cérebro. Algumas horas após o implante o paciente conseguia enxergar formas luminosas, permitindo seu deslocamento no espaço e até reconhecer uma xícara e um pires numa mesa. (BOUWDLER, 2010)

Where the implant is placed

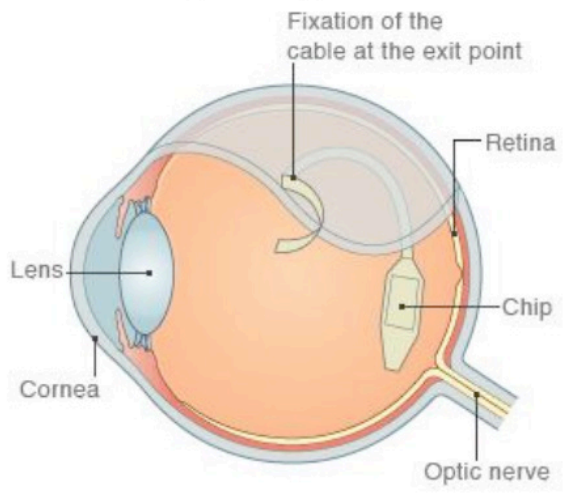

Source: Retina Implant AG
Fig 10. Miika Terho. Implante de chip na retina

Fonte: (BOUWDLER, 2010) Retina Implant AG https://www.bbc.com/news/health-11670044 


\section{- Neil Harbisson}

Neil Harbisson é um artista que nasceu com acromatopsia, enxergando apenas em tonalidades de cinza. Em 2013 iniciou um projeto com o cientista da computação Adam Montandon, que resultou em um sensor eletrônico, que detecta a frequência das cores (Figura 11) e a envia para um chip instalado na parte de trás de sua cabeça, permitindo ouvir o som através da estrutura óssea. Após esse implante Harbisson realizou outro inserindo uma conexão com Internet, para receber outras frequências pela rede. (HARBISSON, 2015)

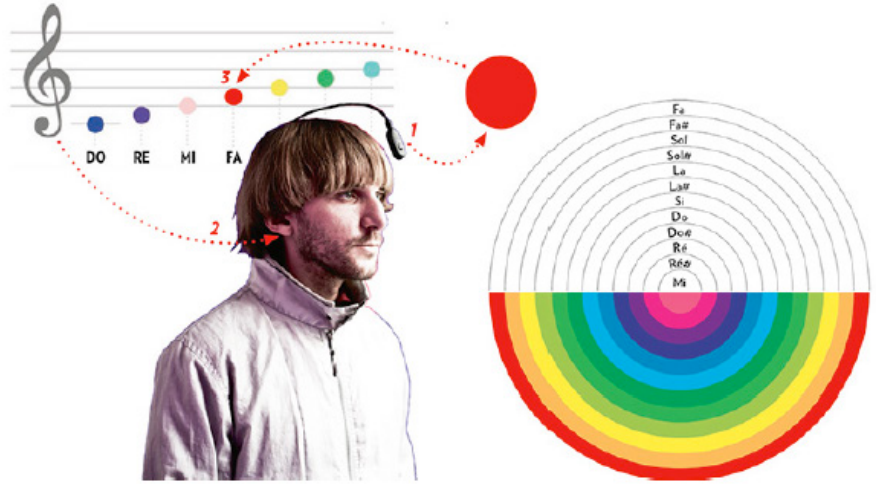

Fig 11. Neil Harbisson - Eyeborg Fonte: H+Pedia, 2018) https://hpluspedia.org/wiki/File:Neil-harbisson-1.jpg

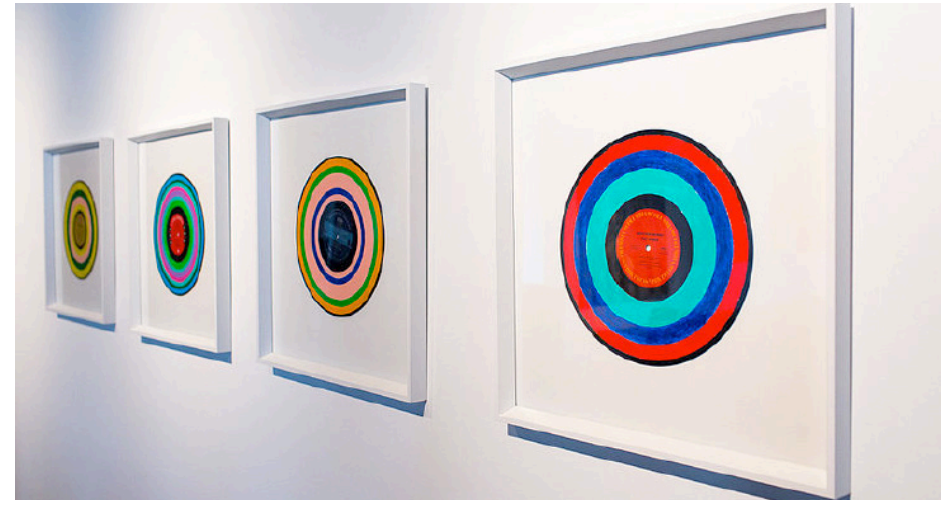

Fig 12. Sonochromatic Records by Neil Harbisson.

Fonte: (WIKIMEDIA COMMONS, 2014) https://commons.wikimedia.org/wiki/ File:Neil_Harbisson_Exhibition.jpg

Aprendeu a traduzir os sons pelas cores (Figura 12), decorando o nome das cores relacionado aos sons, até que isso passou a ser uma percepção natural. Harbisson declara que depois de um tempo começou a sonhar em cores, que a memória das frequências acontecia nos sonhos. Harbisson considera que o dispositivo faz parte dele, tanto que o governo inglês aceitou que no seu passaporte o dispositivo aparecesse, aceitando-o como um ciborgue. Aos poucos os sons cotidianos também passaram a se relacionar com cores. Suas obras são baseadas na tradução do sonoro para o visual, através das cores. No sentido de ampliar a percepção das cores, para além do humano, através desse olho eletrônico, incorporou as frequências do infravermelho e do ultravioleta. (HARBISSON, 2012) 


\section{Organóides}

Embora não se encaixe na modalidade de um implante ainda, e nem sejam dispositivos tecnológicos, os organoides são estruturas tridimensionais, como mini-órgãos, produzidos a partir de células tronco, que se comportam como um órgão real específico.

O tratamento de certas doenças através dessa técnica denomina-se terapia genética ou gênica, que é baseado na introdução de genes sadios, através de manipulação do DNA.

No caso da visão, organoides de retina estão sendo pesquisados para compreensão do funcionamento da retina humana e de doenças. No Instituto de Oftalmologia, da University College London, a equipe do prof. Robin pesquisa a terapia genética, através do transplante de células fotorreceptoras, buscando possibilidades de tratamento de doenças. (ALI, 2012)

O biólogo Robert Johnston, da Universidade Johns Hopkins, busca a produção em laboratório de um organoide de retina humana, para estudo do funcionamento das cores na retina, uma vez que estes possuem todos os tipos de células da retina humana. Esta situação permite que as pesquisas não precisem ser realizadas em camundongos, mas sim como numa retina humana, mas fora do corpo humano. A pesquisa visa também a terapêutica e o reparo da visão. (ELDRED, 2018)

Com os organoides estamos em um estágio onde os dispositivos tecnológicos visuais parecem perder sentido, para o ser humano, embora o conhecimento contribua para a sua utilização dos sistemas visuais artificiais no contexto dos androides.

\section{Visualidade na Máquina}

Como extensão do nosso sistema visual, criamos vários aparatos técnicos, que reproduzem certos aspectos do nosso sistema biológico.

A câmera escura é um aparato tecnológico que reproduz o mesmo fenômeno óptico que acontece no nosso olho. A partir dela construímos vários dispositivos, que captam, registram e reproduzem imagens. A câmera passou por processos de registro foto-químico, magnético e digital. A física, a medicina, a astronomia e outras áreas do conhecimento desenvolveram câmeras específicas para os seus objetivos, nos revelando um universo invisível aos nossos olhos, seja pela visualização do minúsculo, do muito distante ou das diferentes frequências do espectro eletromagnético, que não é visível pelo ser humano. Enxergamos através dessas máquinas, o infravermelho, o ultrassom, os raios X, ultravioleta e ampliamos nossa capacidade de visualização.

Os dispositivos avançaram tecnologicamente, reproduzindo etapas do sistema visual humano, indo do olho ao córtex visual, e passando pelas tecnologias ópticas, elétricas e digitais. 
No contexto da tecnologia digital, surgiu a visão computacional, que proporcionou uma visão às máquinas, que vai além do aspecto óptico, só de captação visual, mas apresenta aspectos cognitivos, como reconhecer diferentes características visuais das coisas, dependendo da especificidade dos softwares utilizados.

Esses dispositivos substituem as atividades da visão humana, principalmente na indústria, visualizando e separando objetos de cores específicas, reconhecendo padrões visuais em determinados materiais como a madeira, ou conferindo a quantidade de elementos em uma embalagem. Também pode ser utilizado em tarefas mais perigosas, onde o ser humano possa ser substituído por uma máquina.

As câmeras utilizadas atualmente são mais sofisticadas, sendo constituídas além das lentes, por sensores, por interfaces de comunicação, e por eletrônica embarcada com inteligência, o que proporciona a visualização combinada com movimentos de braços e mãos robotizados, de acordo com o que enxerga.

Robôs equipados com câmeras podem fazer movimentos com os braços, sendo capazes de visualizar uma bola no ar e pegá-la com a mão. Rollin'Justin é um desses robôs, apresentado em 2008, é equipado com duas câmeras e sensores nas laterais da cabeça, e consegue calcular através da visão binocular o percurso de uma bola jogada para ele, e se movimentar de forma que a bola caia na sua mão e a segure. Consegue pegar até duas bolas ao mesmo tempo, uma em cada mão. Além dessa tarefa, consegue realizar outras, como visualizar e manusear uma máquina de café expresso, encaixando a capsula de café na máquina, ligando-a e servindo o café. (LEIDNER, 2019)

\section{Robôs artistas}

Desde os autômatos, as máquinas através de um conjunto de engrenagens, já conseguiam produzir um desenho, com muitos movimentos complexos. Tal como o autômato de Henri Maillardet, construído por volta de 1800 , que tinha na sua memória quatro desenhos e três poemas. (FRANKLIN, 2019)

No contexto digital, outros sistemas continuaram sofisticando essa tarefa, como o projeto AARON, do artista e programador e professor na Universidade da Califórnia Harold Cohen (1928-2016), que começou a desenvolver em 1973 um programa que desenhasse. Durante toda sua vida Cohen continuou aprimorando o programa, que passou por diversas etapas, ganhando maior complexidade, na programação e nas formas de impressão das imagens. (COHEN, 2019)

Outro projeto que já inclui uma câmera no processo é o Autoportrait (2002), de um grupo alemão chamado Robolab (Figura 13). O sistema é constituído de um braço mecânico industrial, com uma câmera, que capta o rosto de uma pessoa sentada em um banco especialmente localizado, e uma vez captada a imagem, o braço começa a desenhar linearmente o retrato em uma folha de papel em sua frente. (GOMMEL, 2004) 
Fig 13. Neil Autoportrait - Robotlab Fonte: (ROBOTLAB, 2019) http://www. robotlab.de/auto/pics07/autoportrait-mucsarnok03.htm

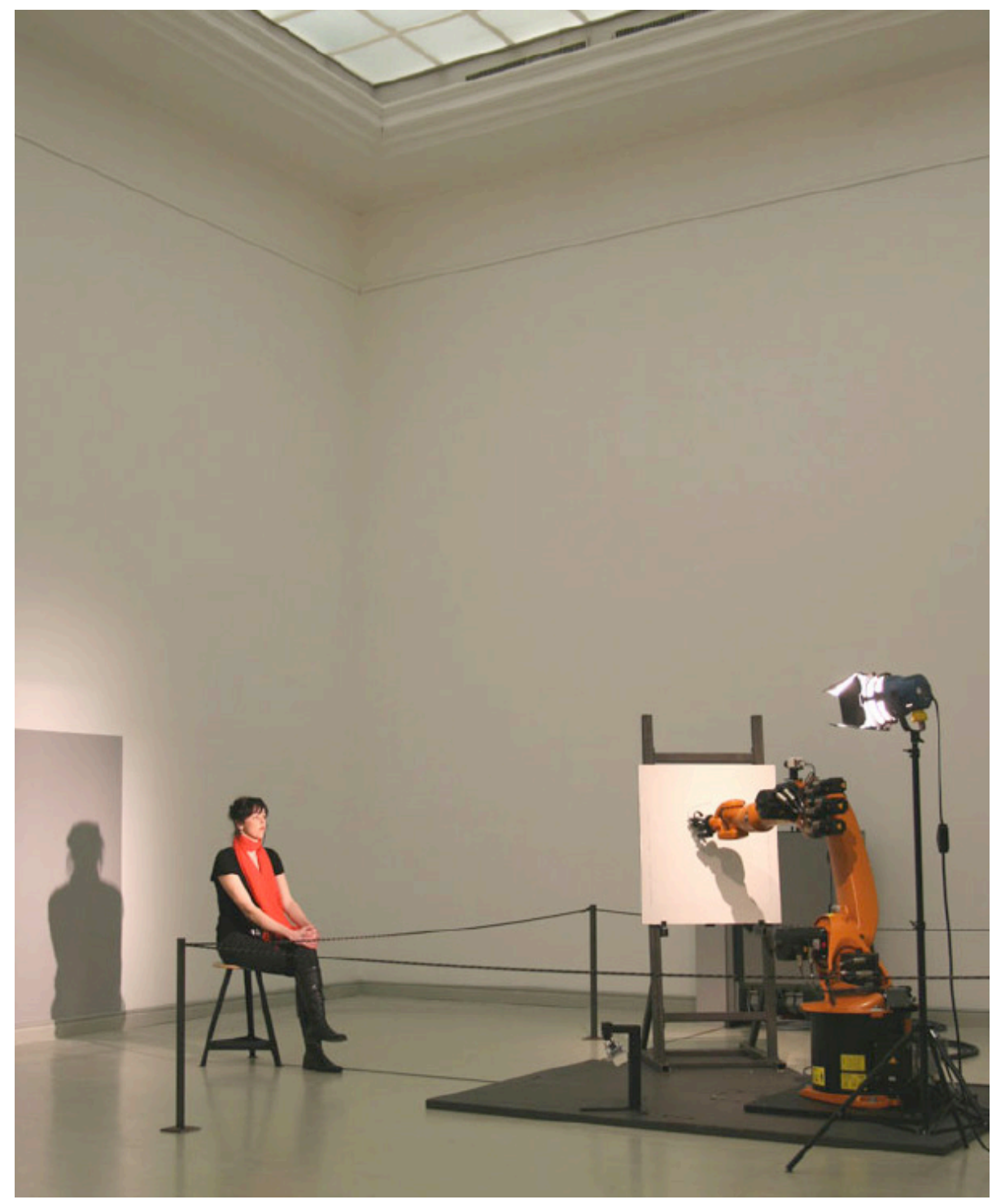

Já a Ai-Da é uma robô humanoide, que também possui câmeras nos seus olhos, que permite a captura de imagem. Seu nome é em homenagem a Ada Lovelace, a primeira programadora da história. Ai-Da é resultado de um projeto de equipe multidisciplinar, com artistas, curadores e cientistas da Universidade de Oxford, Universidade de Leeds, e de uma empresa de Engenharia de Cornawall. Porém, depois que Ai-Da traça linearmente os esquemas, que não são só retratos, é preciso que uma pessoa, a artista Suzie Emery, aplique a tinta nas formas. (AMBROSIO, 2019, 38, 39)

Os artistas têm explorado muito o recurso de câmeras e inteligência artificial, mas não em máquinas humanoides. Mas a visualização no contexto da inteligência artificial, tem se desenvolvido muito, principalmente com os sistemas de reconhecimento facial ou de objetos, podendo surgir obras além da produção de imagens. 


\section{Considerações finais}

O ser humano encontra-se numa etapa de sua evolução, onde suas transformações corporais não são apenas resultados das atividades físicas e condições ambientais, como foi a maior parte do tempo, na sua história, mas são a sua própria interferência no design do seu corpo. Simultaneamente encontra-se num nível de construção de suas extensões artificiais, que se aproxima cada vez mais do biológico. Encontramo-nos discutindo o que é o humano, o que é inteligência, a consciência, a emoção, a alma, e as fronteiras entre natural e artificial, biológico e tecnológico, ficam cada vez mais borradas. No contexto da medicina, todos os conhecimentos científicos e tecnológicos parecem fazer sentido, na busca de soluções dos problemas físicos do ser humano, mas no contexto social e ético, a capacidade de controlarmos a vida torna-se uma discussão cada vez mais complexa e polêmica.

A visão nosso tema em questão aqui, como parte desse movimento todo, permite que espelhe essas transformações como um todo. Vimos que a relação de elementos de um sistema visual humano, com elementos de um sistema visual artificial, vem acontecendo em diversos níveis, mas sempre alterando o ser humano e as máquinas, que se aproximam cada vez mais da singularidade tecnológica, do olho ao córtex visual.

$\mathrm{O}$ design e a arte participam desse movimento, construindo materialmente esse universo e apresentando questões para a sociedade, numa gama que vai do apocalíptico ao admirável.

\section{Referências}

ALI, Robin. Gene and stem cell therapy for retinal disorders. In Vision Research, Visionary of the quarter, 2012. Disponível em http://www.vision-research.eu/index.php?id=696 Acesso em 14/11/2019

AMBROSIO, Chiara. Unsettling robots and the future of art. In Science, vol. 365, n. 6448, 05/07/2019. Disponível em https://science.sciencemag.org/content/365/6448/38.full.pdf Acesso em 17/11/2019

BOUWDLER, Neil. Implanted chip 'allows blind people to detect objects. BBC News. 3/11/2010. Disponível em https://www.bbc.com/news/health-11670044 Acesso em 12/11/2019 COHEN, Harold. Official homepage. Disponível em http://www.aaronshome.com/aaron/index.html Acesso em 16/11/2019

CONFORTI, Claudinéia. UNINTER. 16/08/2017. Secretaria deficiente usando Mouse Ocular. Disponível em http://pedagogiauninterbarracao.blogspot.com/2017/08/mouse-ocular-uma-tecnologia-avancada.html Acesso em 17/11/2019

CREATORS Project. [Vídeo] Colônias | Vik Muniz e Tal Danino Transformam Células Vivas em Arte. In Vice Brasil. 20/08/2014. Disponível em https://www.vice.com/pt_br/article/ 8qdy4x/colonias-vik-muniz-e-tal-danino-transformam-celulas-vivas-em-arte Acesso em $17 / 11 / 2019$

DAUGHERTY, Anna. The Extraordinary Artwork of Francis Tsai. In Medium, The Alcade. Mar 30, 2015. Disponível em https://medium.com/the-alcalde/the-extraordinary-artwork-of- 
-francis-tsai-1d9cfe58894. Acesso em 14/11/2019.

DEDAVID, Berenice Anina; GOMES, Carmen Isse e MACHADO, Giovanna. Microscopia eletrônica de varredura: aplicações e preparação de amostras : materiais poliméricos, metálicos e semicondutores [recurso eletrônico] - Porto Alegre : EDIPUCRS, 2007. Disponível em http:// www.pucrs.br/edipucrs/online/microscopia.pdf Acesso em 13/10/2019

DOBELLE, W. H. Artificial Vision for the Blind by Connecting a Television Camera to the Visual Cortex In ASAIO Journal 2000; 46:3-9. Disponível em https://pdfs.semanticscholar. org/1777/93b5b3f7d8610b159e7da4a85013db60acdd.pdf Acesso em 13/11/2019

Eldred, Kiara et all. Thyroid hormone signaling specifies cone subtypes in human retinal organoids. Science Journal, vol. 362, month 10, 2018.

ENLIGHTENMENT MATTER. To see or not to see. 29/04/2006

https://enlightenmentmatters.wordpress.com/?s=leonardo+da+vinci

ENOCH, Jay M. "The Enigma of Early Lens Use.” Technology and Culture, vol. 39, no. 2, 1998, pp. 273-291. JSTOR, Disponível em https://www.jstor.org/stable/3107047?read-now=1\&seq=2\#page_scan_tab_contents. Acesso em 10/10/2019

ÉVORA, Fátima Regina Rodrigues. A descoberta do telescópio: fruto de um raciocínio dedutivo? Cad. Cat. Ens. Fís., Florianópolis, 630 (Número especial): 30-48, jun. 1989. Disponível em file:///C:/Users/Milton\%20Sogabe/Downloads/10068-50438-1-PB.pdf Acesso em $12 / 10 / 2019$

FRANKLIN - The Flanklin Institute. Maillardet's Automaton. Disponível em https://www. fi.edu/history-resources/automaton Acesso em 16/11/2019

GOMMEL, Matthias; HAITZ, Martina; ZAPPE, Jan. Autoportrait. Robotlab, 10/01/2004. Disponível em http://www.robotlab.de/auto/portrait_en.htm Acesso em 17/11/2019

HARARI, Yuval Noah. Homo Deus: uma breve história do amanhã. São Paulo, Companhia das Letras, 2016.

HARBISSON, Neil. I listen to colours. TEDGlobal 2012 | June 2012. Disponível em https:// www.ted.com/talks/neil_harbisson_i_listen_to_color\#t-505090 Acesso em 15/11/2019 HARBISSON, Neil. D\&AD President's Lecture. D\&AD - Creative Advertising, Design and Digital. 2015. Disponível em https://www.youtube.com/watch?v=2lHPpyRZujM Acesso em $15 / 11 / 2019$

HELDEN, Albert Van. The beginnings, from Lipperhey to Huygens and Cassini. Experimental Astronomy. 2009.

Hofstetter, Henry W. \& Graham, Robert. Leonardo and Vision Science.

Optometry and Vision Science: January, Volume 30 - Issue 1. 1953. ppg 41-44 Disponível em https://journals.lww.com/optvissci/Fulltext/1953/01000/LEONARDO_AND_CONTACT_ LENSES_.11.aspx Acesso em 14/11/2019.

HOGG, Jabez. Microscope: its history, construction and application. London, The Ilustrated London Library. 1854. Disponível em https://books.google.com.br/books?hl=p$\mathrm{t}-\mathrm{BR} \& \mathrm{lr}=\& \mathrm{id}=\mathrm{AAC} 9 \mathrm{AAAAYAAJ} \& \mathrm{oi}=\mathrm{fnd} \& \mathrm{pg}=\mathrm{PA} 4 \& \mathrm{dq}=$ history + microscope $\&$ ots $=5$ Veelt $4 \mathrm{hZ}-$ $\mathrm{f} \&$ sig=doW6BASCBiCaHNS-xf9xaTM9Az0\#v=onepage\& $\mathrm{q}=$ history\%20microscope \&f=false Acesso em 13/10/2019.

HUBBLE, Hubble site. NASA. Disponível em https://hubblesite.org/ Acesso em 17/11/2019 H+Pedia. File: Neil-harbisson-1.jpg. 13/11/2018. Disponível em https://hpluspedia.org/ wiki/File:Neil-harbisson-1.jpg Acesso em 11/11/2019

KURZWEIL, Ray. The Singularity is Near. Penguin Group, 2005. Disponível em http://stargate.inf.elte.hu/ seci/fun/Kurzweil,\%20Ray\%20-\%20Singularity\%20Is\%20Near,\%20The\%20 
\%28hardback\%20ed\%29\%20\%5Bv1.3\%5D.pdf Acesso em 16/11/2019.

LAUFER, B. (1915). Optical Lenses: I. Burning-Lenses in China and India. T'oung Pao, 16(2), second series, 169-228. Disponível em http://www.jstor.org/stable/4526448 Acesso em $10 / 10 / 2019$

LEIDNER, Daniel; DIETRICH, Alexander. Rollin' Justin. Institute of Robotics and Mechatronics. German Aerospace Center. Disponível em https://www.dlr.de/rm/en/desktopdefault. aspx/tabid-11427/\#gallery/28335 Acesso em 12/11/2019

LOPER, Adriane Aparecida e MARTINS, João Batista. Mouse Ocular: tecnologia para comunicação. In X Congresso Nacional de comunicação. Pontifícia Universidade Católica do Paraná, Curitiba, 2011. P.13537-13548.

MOON, Jin-Hee; Dong Hyun Baek, Yoon Young Choi, Kwang Ho Lee, Hee Chan Kim, Sang-Hoon Lee. Wearable polyimide-PDMS electrodes for intrabody communication. In Journal of Micromechanics and Microengineering. Vol.: 20, Number 2, February, 2010.

PERES, Carolina. O corpo, a câmera e o ato de fotografar. In CARVALHO, Agda e LEOTE, Rosangella. Body/object/Space: Perceptions and Transductions. DATJournal, v.3 n.1 2018. P. 94-108. Disponível em https://datjournal.anhembi.br/dat/article/view/74/65 Acesso em 11/11/2019. DOI: https://doi.org/10.29147/dat.v3i1

PERKINS, Robert. Lensless Camera: Ultra-Thin Camera Creates Images Without Lenses In Caltech, June 21, 2017 Disponível em

https://www.caltech.edu/about/news/ultra-thin-camera-creates-images-without-lenses-78731 Acesso em 06/11/2019

ROBOTLAB. Autoprotrait. 2019 Disponível em http://www.robotlab.de/auto/pics07/autoportrait-mucsarnok03.htm Acesso em 17/11/2019.

ROSSI, Paolo. Os filósofos e as máquinas: 1400-1700. São Paulo, Companhia das Letras. 1989. SANTOS FILHO, Sebastião G. dos. AFM E STM: microscopias de força atômica e tunelamento. LSI/PSI/EPUSP. Disponível em http://www.lsi.usp.br/ acseabra/pos/5749_files/AFM_STM. pdf Acesso em 15/10/2019

SCHOR, Paulo. Óptica Fisiológica e Cirurgia Refrativa; Tese (Livre Docência em Oftalmologia) Universidade Federal de São Paulo - Escola Paulista de Medicina. 2003

SINES, George and SAKELLARAKIS, Yannis A. "Lenses in Antiquity." American Journal of Archaeology, vol. 91, no. 2, 1987, pp. 191-196. JSTOR, Disponível em www.jstor.org/stable/505216 Acesso em 10/10/2019

SOKOL, Zach. [Exclusive Video] Creating Sand Castles With A Single Grain of Sand. In Vice. Mar 27 2014. Disponível em

https://www.vice.com/en_us/article/xy4zj3/creating-sand-castles-with-a-single-grain-of-sand Acesso em 17/11/2019

SPENCE, Rob. Rob Spence - Eyeborg, the Enhanced Self. TEDXBrussels, 2011. Disponível em https://eyeborgproject.tv/ted-talks/ Acesso em 15/11/2019

TSAI, Francis. Oficial webpage. Disponível em http://teamgt.com/ Acesso em 14/11/2019 VOYAGER, NASA, Jet Propulsion Laboratory. Disponível em https://voyager.jpl.nasa.gov/ Acesso em 17/11/2019

Recebido: 02 de novembro de 2019. Aprovado: 29 de novembro de 2019.
WIKIMEDIA COMMONS. Sonochromatic Records by Neil Harbisson. Exhibited in New York. 20/08/2014. Disponível em https://commons.wikimedia.org/wiki/File:Neil_Harbisson_ Exhibition.jpg?uselang=pt-br Acesso em 11/11/2019 